\title{
METHOD FOR DETECTION OF DEVELOPING DEFECTS IN HIGH-VOLTAGE POWER TRANSFORMERS BY RESULTS OF THE ANALYSIS OF DISSOLVED OIL GASES
}

\author{
Oleg SHUTENKO \\ Department of Electric Power Transmission Electric Power Faculty, National Technical University "Kharkov Polytechnic Institute", \\ 2, Kyrpychova str., Kharkov, 61002, Ukraine, Tel.: +421 5770766 43, E-mail: o.v.shutenko@gmail.com
}

\begin{abstract}
The article describes a method for detecting developing defects in high-power oil-filled transformers, based on the results of analysis of dissolved gases in oil. It has been found that an early diagnostic sign of development of ionization processes of aging and thermal degradation in transformers' isolation is the appearance of a systematic trend in the time dependencies of hydrocarbon gas content. Though, exceeding the concentrations of gases regulated by boundary values (the traditional criterion) does not always reflect the damage to the insulation, it often being reversible.
\end{abstract}

Keywords: dissolved gas analysis, interpretation of transformer faults, dependency of concentrations of gases on time of operating, trend, correlation, the rule of taking a decision

\section{INTRODUCTION}

Currently, one of the most common methods of diagnosis of the condition of high voltage power transformers is analysis of gases dissolved in oil (DGA). It is known that this method enables to recognize up to $80 \%$ of all defects in transformers. The method is based on the fact that any thermal or discharge processes in transformer insulation leads to its destruction and the formation of gases that are dissolved in oil. Each type of defect has its own spectrum of gases. To interpret the results of DGA, the world's leading energy and transformer-building companies are using several criteria: a criterion for boundary concentrations, a criterion for the rates of increase in gases, and the ratio of gas pairs. For each of the criteria, the known standards [1-7] regulate the boundary values, which differ significantly from each other. The studies performed in [8] showed that the use of boundary values of gas concentrations recommended by these methods is accompanied by erroneous decisions. At the same time, the lowest risk value occurs when the boundary values of gas concentrations recommended by IEC 60599 are used [1]. In [9] it was shown that the greatest reliability in the recognition of the type of defect is provided by the ratios of gases that are recommended by the method of IEC 60599. Despite this improvement in the methods, and the criteria used to interpret the results of the DGA, is being actively pursued. The main areas of improvement are both the adjustment of the boundary values of the concentrations and rates of gas growth [1012], the search for the use of new gas vapor ratios [13], and the development of graphical methods of interpretation [14-16]. A large number of publications [17-18] is devoted to the use of fuzzy logic and neural networks for interpreting the results of DGA. It should be noted that in most publications, are mostly refined the boundary values of the criteria used, and the dynamics of their change over time are not practically studied, which limits the possibilities for early detection of developing defects. This article describes the method for early detection of defects in high-voltage transformers, in which the criterion for the presence of a defect is not the numerical values of gas concentrations, as in most known techniques, but the nature of their variation over time.

\section{A RESEARCH OF DEPENDENCIES OF CONCENTRATIONS OF GASSES DISSOLVED IN OIL ON THE DURATION OF OPERATION}

As a training sample the results of chromatographic analysis of dissolved gases in oil for 426 transformers from 6 regions of Ukraine were used. Fig. 1 shows the concentrations of dissolved gases in oil hydrocarbon series the duration of operation, as well as the maximum values of concentrations, which are used in Ukraine [5]. The same figure shows the results of analysis of gases dissolved in oil in 1167 faulty transformers. (Shown in Fig. 1 red.) The figure shows that there are transformers that do not have defects (marked in Fig. 1 green), for which the values of gas concentrations exceed the appropriate limit values while for some "defective" transformers gas concentrations despite of there being a defect are within acceptable values. This leads to the fact that the function of gas concentration distribution density for defect-free and defective condition of transformers intersect [19], show Fig. 2. Therefore it is not possible to select the boundary value gas concentrations that would not give wrong decisions. It is also clear that the tightening of the maximum values will lead to a sharp increase in the error I - the type I (false alarm). It was therefore decided to consider not only the quantity of gases released, but the dynamics of their changes during the diagnosed period of time.

The results of measuring of concentrations of gases are presented as follows:

$\vec{x}(t)=\vec{G}(t)+\vec{\eta}(t)+\vec{\xi}(t)$

where: $\vec{G}(t)$ - constant component, which characterizes the irreversible changes in the object (regular trend); $\vec{\eta}(t)$ - reversible changes (due to the predominance of diffusion of gases from the oil into the atmosphere); $\vec{\xi}(t)$ - the total error of the methodology for conducting DGA (due to errors in sampling, changes in gas concentrations during storage and transportation, systematic and random errors in the methodology for conducting DGA). 

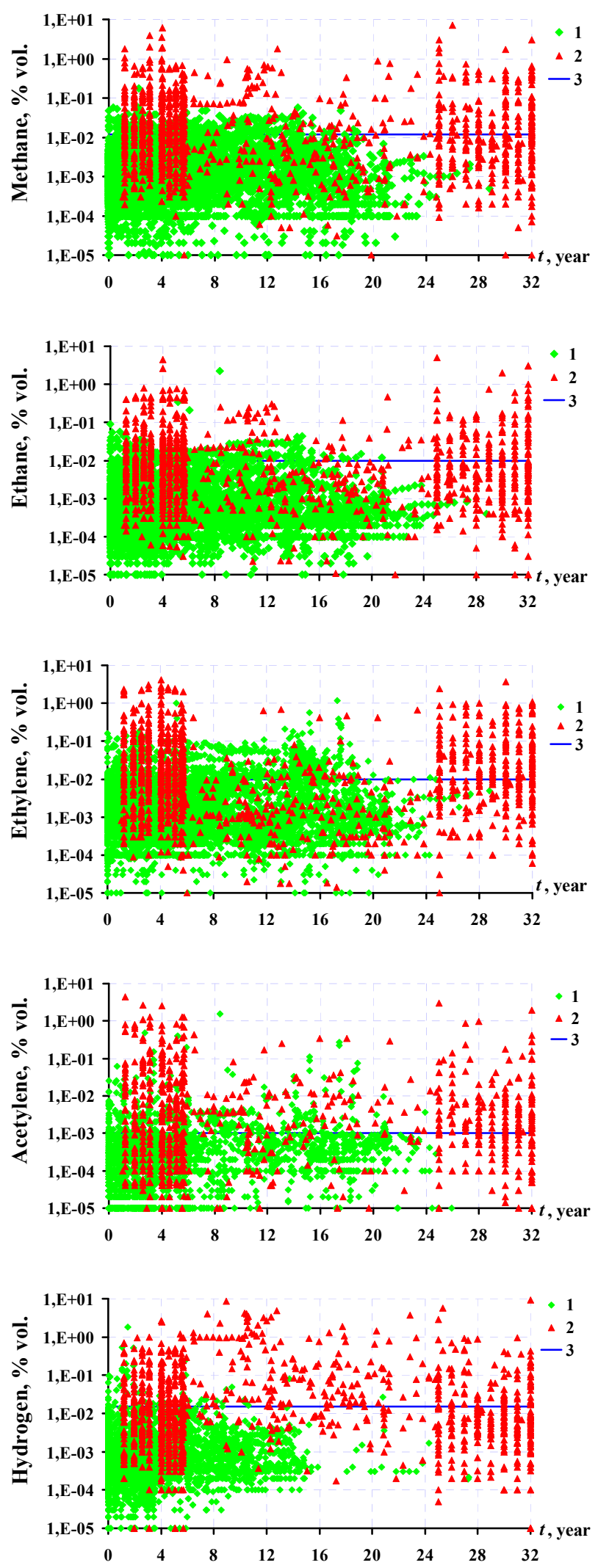

1 - for transformers without defects; 2 - for defective transformers at the moment of detection of a defect; 3 - maximum values of gases

Fig. 1 Dependencies of change of concentration of gases on duration of operation

The conducted analysis has shown that for the defective transformers, diagnosed at the interval of time the systematic component exceeds significantly the noise components (see Fig. 3). This trend is not observed in natural aging of oil.
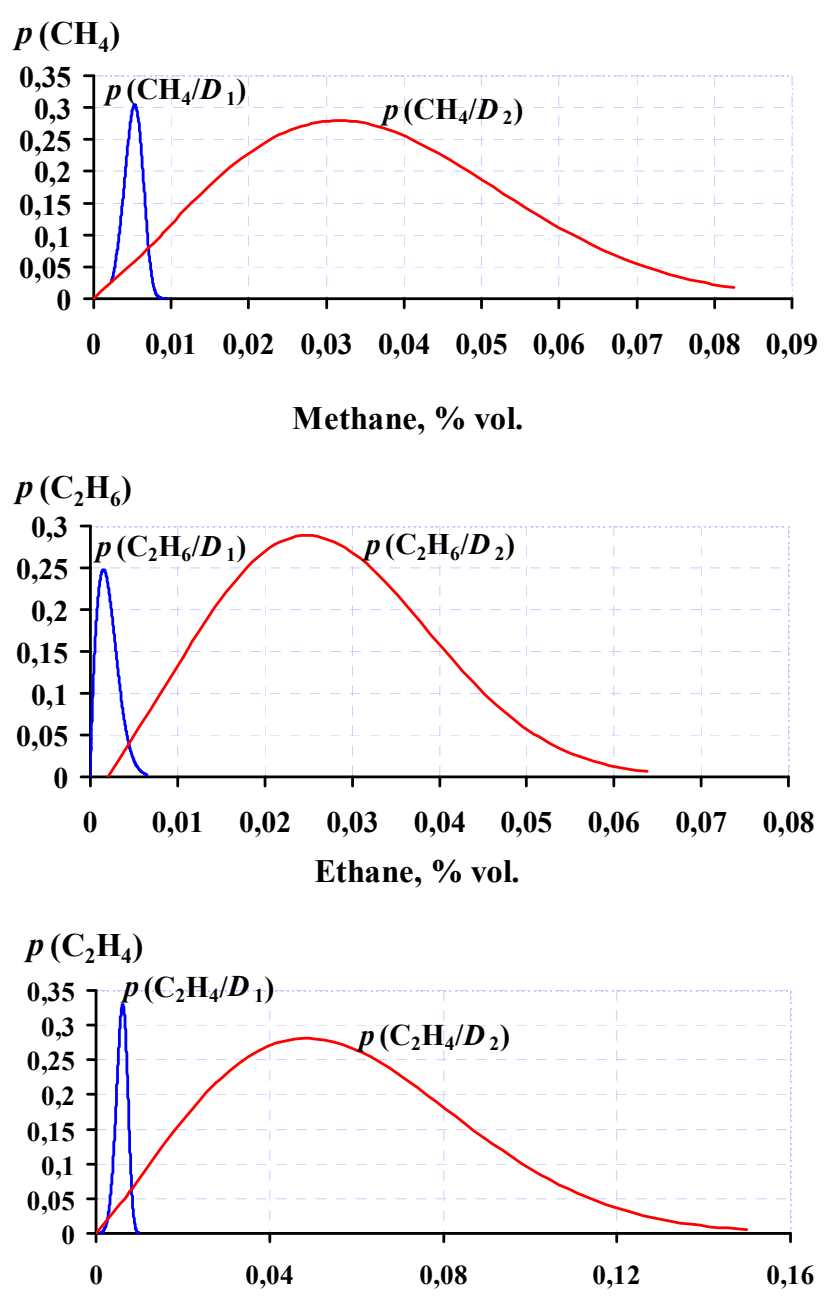

Ethylene, \% vol.
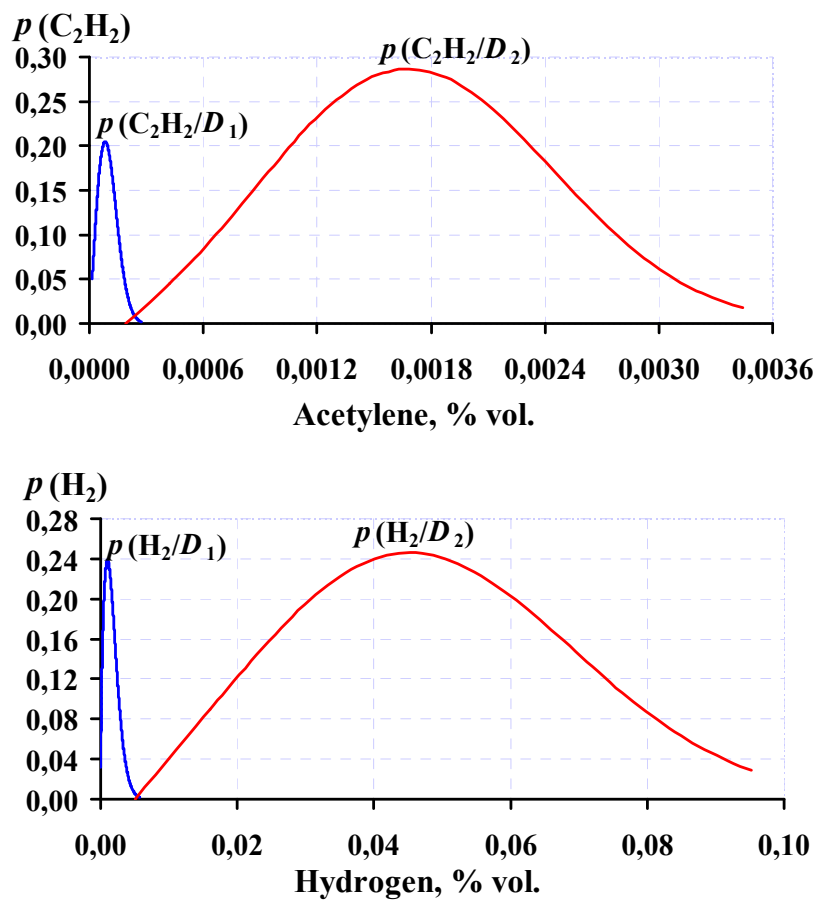

Fig. 2 Density functions distribution of gas concentrations for defect-free $\left(\boldsymbol{D}_{1}\right)$ and faulty $\left(\boldsymbol{D}_{2}\right)$ condition of transformers 
The research showed that dependencies of hydrocarbon gases on the time of operating in the absence of a defect and the absence of effects of operational factors are of stochastic, random nature, i.e. the dominant are noise components $\bar{\eta}(t)$ and $\xi(t)$, which is illustrated in Fig. 4. However, the excess of the systematic component $\bar{G}(t)$ above the noise components $\vec{\eta}(t)$ and $\vec{\xi}(t)$ was found not only in the transformers that were defective. There was found a group of transformers, for which there was significant excess of the regular components over the noise ones. At the same defects in these transformers were absent. Interesting is the fact that the concentrations of dissolved gases in oil significantly, in some cases up to several times, exceeded the maximum values.

Since some of the transformers showed a tendency to decrease of concentrations of dissolved gases in oil, it has been hypothesized that the reason for the increase of concentrations of dissolved gases in oil are the external influences. Therefore, further studies were devoted to analysis of operational influences on the change in concentrations of dissolved gases in oil. The analysis of excess of dissolved gases' concentrations in oil of their maximum values in defect-free transformers [20, 21] revealed a number of key reasons:

1. Incorrect calibration of the chromatograph. Prior to the analysis the chromatograph is calibrated not to the special gauge oils and oils for transformers with a known diagnosis. This may lead to the fact that the measured concentrations of dissolved gases in oil may several times exceed allowable values, see Fig. 4 . In this case, it is quite easy to identify the cause of the growth of concentrations of gases, since increasing concentrations of gases occur simultaneously on all substation transformers, see Fig. 4.

2. The influence of operational factors. It is known [6, $20,21]$ that increasing concentrations of gases in oil of defects-free transformers can be caused by the following factors:

- Increasing load of transformers;

- Mixing of fresh oil with the remnants of the old one, saturated with gases, located in the cooling system, the tanks of regulation under loading device, expander, etc.;

- Refilling with oil, which had been in operation and containing dissolved gases;

- Conducting welding on the tank;

- Damage to the oil pump with unscreened stator; oil's overheating by thermal electric heater at its processing in degassing and other facilities; flow of gases from the tank contactor of the device of regulation under load into the tank of the transformer with a load tap changer types of PC-3 and PC-4; seasonal changes in the intensity of the aging process, etc.

In case of an overload or overvoltage, the concentration of $\mathrm{CO}_{2}$ and $\mathrm{CO}$ usually increases two or more times as compared with the maximum values, for example, due to failure or malfunctioning of the arresters, circuit breakers, lightning and switching overvoltage, phase mismatch, a short circuit in an electrically connected network etc.
Such transformers must be monitored. If the reason for the growth of concentration relates to the abovementioned cases, the concentration will return to the original within 1or 2 months.
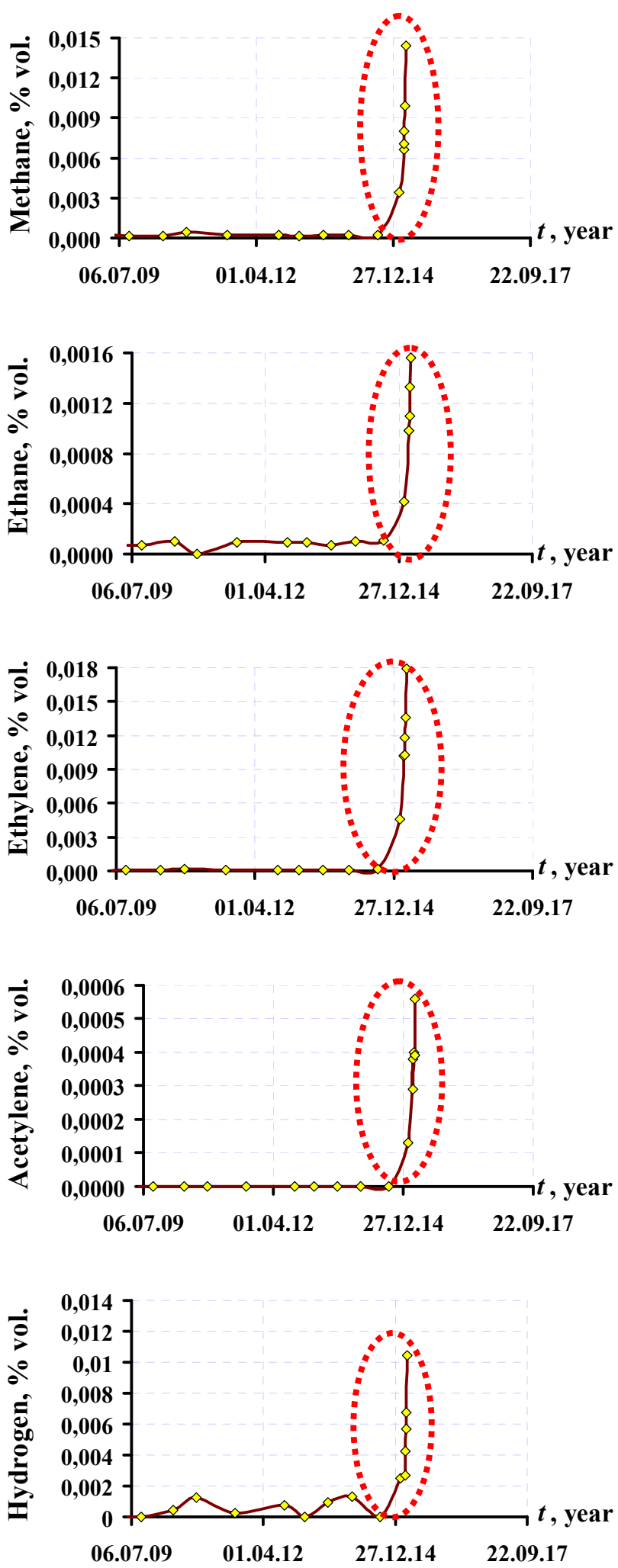

Fig. 3 Dependency of concentrations of gases on time of operating for the defect transformers (overheating with a temperature above $700^{\circ} \mathrm{C}$, which is accompanied by discharges for transformer TDTN $40 \mathrm{MVA}, 110 \mathrm{kV}$ )

Fig. 5 shows the concentrations of dissolved gases in oil at transformer substation "Mine 21" of Lugansk 
Electricity-distributing Company. The results of chromatographic analysis of 27.02 .2007 showed that in the transformer T-2, the concentration of gases $\mathrm{CO}, \mathrm{CH}_{4}$, $\mathrm{C}_{2} \mathrm{H}_{4}$ exceed the maximum values. To elucidate the reasons for the increase of concentrations of gases in the transformer, thermal control was held, which showed a temperature rise of oil in the tank of the transformer. The reason for the overheating was a damage of contact connections on the low side of transformer T-2, Phase A.
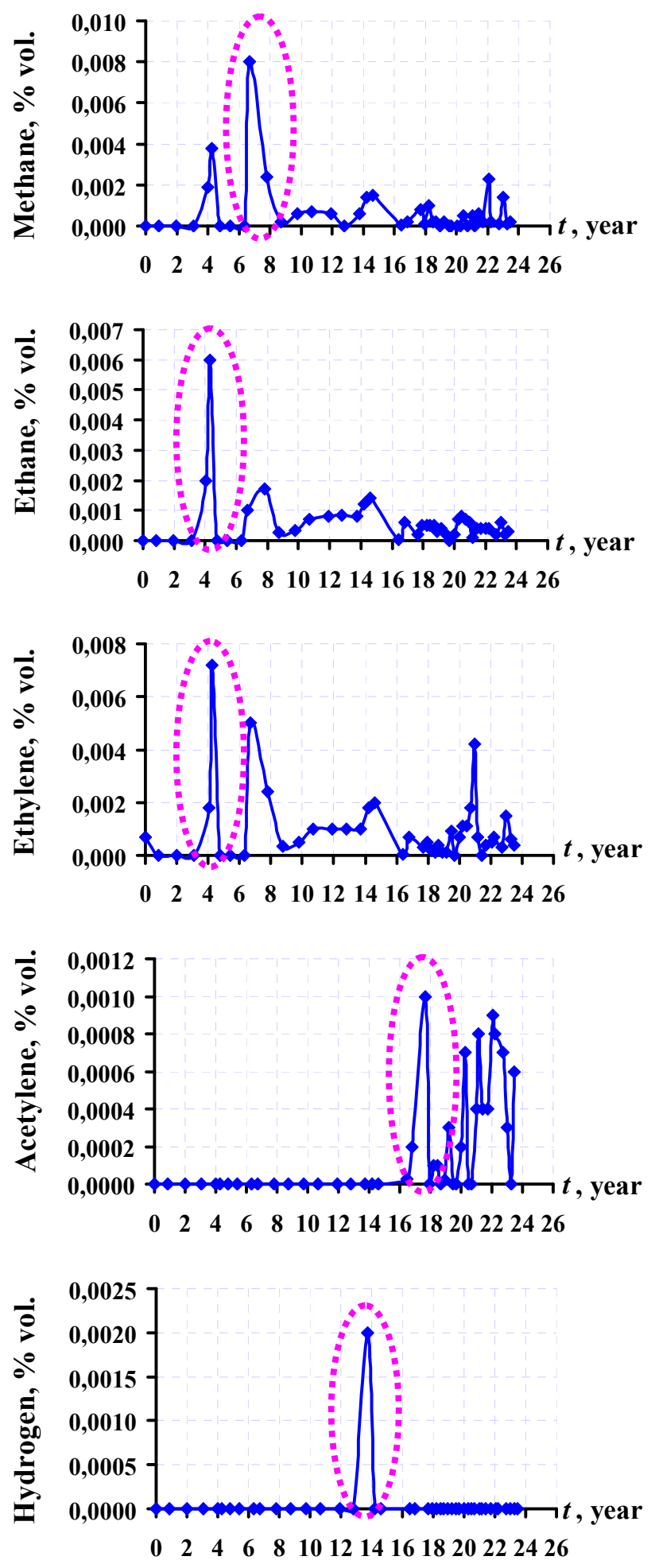

Fig. 4 Dependency of concentrations of gases on time of operating for the fault-free transformers (transformer TDTN 40 MVA, $110 \mathrm{kV}$ )
However, the most critical in terms of decisionmaking, the situation becomes precisely at the moment when the concentration of dissolved gases in oil reaches the highest value and exceeds the maximum concentration.
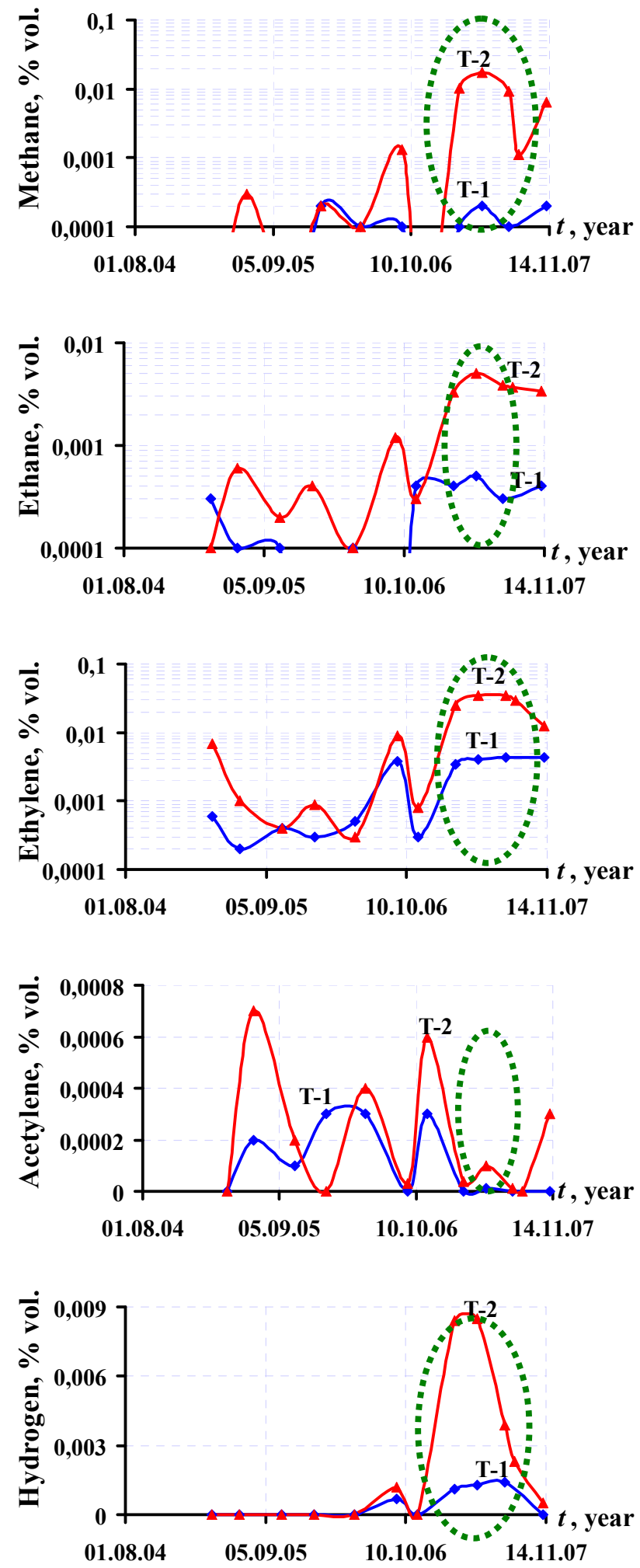

Fig. 5 Dependence of concentrations of dissolved gases in oil transformer substation "Mine 21", Lugansk Electricitygeneration Company on the time of operation

If there is no information about such influences (which is usually the case) the increase in concentrations of 
dissolved gases in oil may be erroneously interpreted as a defect (an error of I-first type). In this case, the recommendation may be issued (and absolutely correctly) to take samples after a few days, but if this is the fastest growing defect, it can be overlooked (an error of II-the first type). After replacing the tires and tightening of all the bolted joints gas concentration began to decline gradually.

It is established that such operational effects are felt not only on the concentration of gases in the diagnosed transformer, but also on the concentration of gases in nearby transformers at substations, see Fig. 6.
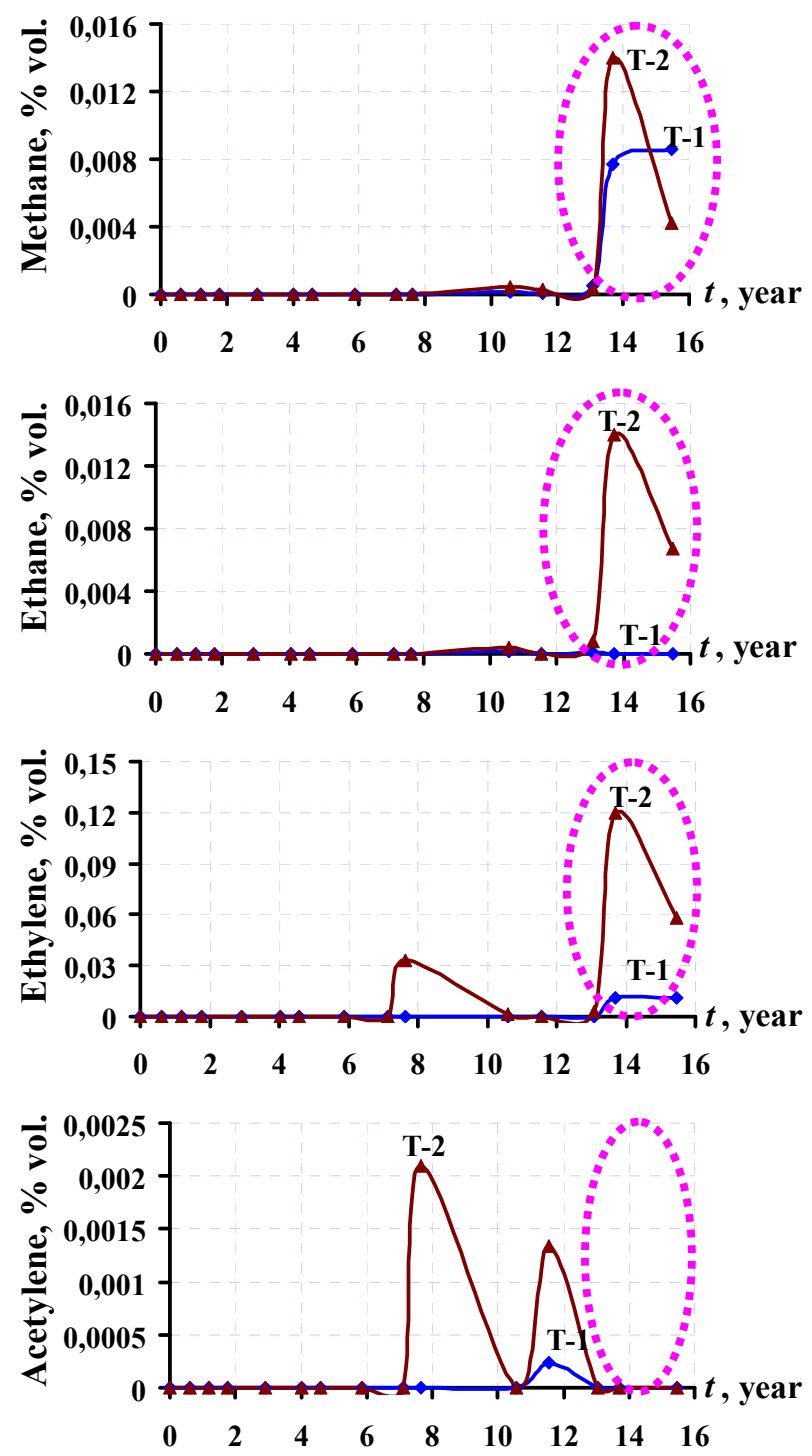

Fig. 6 Dependence of concentrations of dissolved gases in oil transformer - transformer substation «Buryn», Sumy

Electropower Company on the time of operation

To identify the growth of concentrations of gases, which is caused by external influences, in [21] it is suggested to use the following correlation between gases in adjacent transformers in the analyzed time interval:

$$
r=\frac{\sum_{i=1}^{n}\left(y_{i}-\bar{y}\right) \cdot\left(x_{i}-\bar{x}\right)}{\sqrt{\sum_{i=1}^{n}\left(y_{i}-\bar{y}\right)^{2} \cdot \sum_{i=1}^{n}\left(x_{i}-\bar{x}\right)^{2}}},
$$

where: $y_{i}$ - the current value of the concentration of $i$ - th gas in the transformer diagnosed; $x_{i}$ - the current value of the concentration of $i$ - th gas in the adjacent transformer; $\bar{y}$ - the expected concentration of $i$ - th gas in the transformer diagnosed; $\bar{x}-$ the expected concentration of $i$ - th gas in the nearby transformer; $n$ - the volume of sample values.

Decision on the significant correlation between the gases of adjacent transformers is taken if calculated, sample coefficient of pair correlation exceeds a critical value, with the number of degrees of freedom $n-2$ and the confidence probability $p=0,95$. As seen in Figure 6, despite the fact that the concentrations of methane, ethylene and ethane in the transformer T-2 highly exceed the value of similar concentrations of gases in the transformer $\mathrm{T}-1$, the trend in changes of gas concentrations in the time interval considered is identical for both transformers. This is confirmed by the values of the coefficients of pair correlation between the gases in adjacent transformers, which are given in Table 1. Of the seven pairs of analyzed gases, a significant correlation was identified between the $\mathrm{CO}, \mathrm{C}_{2} \mathrm{H}_{4}, \mathrm{C}_{2} \mathrm{H}_{6}$ and $\mathrm{H}_{2}$, indicating a common cause of rising concentrations of gases in adjacent transformers.

Table 1 The values of the coefficients of pair correlation between the gases dissolved in oil transformers T-1 and T2 for substations "Mine 21" and "Buryn"

\begin{tabular}{|l|c|c|}
\hline \multirow{2}{*}{ Gases } & \multicolumn{2}{|c|}{ Transformers } \\
\cline { 2 - 3 } & $\begin{array}{c}\text { Stn «Mine» } 21, \\
\boldsymbol{N}=\mathbf{1 1}, \rho_{\text {critical, }}, \\
\mathbf{0 , 9 5}=\mathbf{0 , 6 0 2}\end{array}$ & $\begin{array}{c}\text { Stn «Buryn», } \\
\mathbf{N = 1 5}, \boldsymbol{\rho}_{\text {critical, 13, }} \\
\mathbf{0 , 9 5}=\mathbf{0 , 5 1 4}\end{array}$ \\
\hline $\mathbf{C O} / \mathbf{C O}$ & $\mathbf{0 , 8 9 6}$ & - \\
\hline $\mathbf{C O}_{\mathbf{2}} / \mathbf{C O}_{\mathbf{2}}$ & 0,564 & $\mathbf{0 , 8 0 2}$ \\
\hline $\mathbf{H}_{\mathbf{2}} / \mathbf{H}_{\mathbf{2}}$ & $\mathbf{0 , 8 7 0}$ & - \\
\hline $\mathbf{C H}_{\mathbf{4}} / \mathbf{C H}_{\mathbf{4}}$ & 0,565 & $\mathbf{0 , 8 3 2}$ \\
\hline $\mathbf{C}_{\mathbf{2}} \mathbf{H}_{\mathbf{6}} / \mathbf{C}_{\mathbf{2}} \mathbf{H}_{\mathbf{6}}$ & $\mathbf{0 , 6 7 0}$ & $\mathbf{- 0 , 0 8 9}$ \\
\hline $\mathbf{C}_{\mathbf{2}} \mathbf{H}_{\mathbf{4}} / \mathbf{C}_{\mathbf{2}} \mathbf{H}_{\mathbf{4}}$ & $\mathbf{0 , 8 2 2}$ & $\mathbf{0 , 9 0 3}$ \\
\hline $\mathbf{C}_{\mathbf{2}} \mathbf{H}_{\mathbf{2}} / \mathbf{C}_{\mathbf{2}} \mathbf{H}_{\mathbf{2}}$ & 0,577 & 0,494 \\
\hline
\end{tabular}

To reduce the concentrations of dissolved gases in oil the following operational factors are applied [4]:

- Purging transformers with nitrogen with nitric protection of oils,

- Reducing the load of the transformer,

- Replacement of silica gel,

- A long power disconnection,

- Degassing of oil,

- Refilling with degassed oil,

- Partial or complete replacement of oil in the tank of the transformer,

- Filling with oil under vacuum, including a partial vacuum,

- Replacement of oil in the oil line, hanging bins, expansion tanks, selector device of regulation under load, etc.

In addition, the analysis showed that the decrease in concentrations of dissolved gases in oil is due to the appearance of the interim period between the date of 
sampling and the date of the chromatographic analysis. In some cases, such intervals were 100 days or more, which inevitably led to reduced concentrations of dissolved gases in oil in the sample due to diffusion of gases into the atmosphere [20]. It should also be taken into account that sampling is done periodically and there is always a possibility that a defect may develop between the dates of the tests.

\section{THE METHOD TO INTERPRET CHROMATOGRAPHIC ANALYSIS OF GASES DISSOLVED IN OIL}

To verify the importance of the systematic component the coefficient of pair correlation was used. We determined:

1. The values of the coefficients of pair correlation between the concentrations of dissolved gases in oil and duration of operation (the hypothesis of the presence of significant growth in concentrations of at least one of the gases is checked);

2. The values of the coefficient of pair correlation between the gases in the transformer diagnosed (test the hypothesis of a simultaneous increase in the concentrations of gases is checked);

3. The values of the coefficient of pair correlation between the concentrations of the same gas in a diagnosed and adjacent transformers (hypothesis about the presence or absence of operational influences is tested).

The analysis of dependencies of gases on the operating time for all of the analyzed samples has allowed to classify four possible options for the behaviour of gases in the analyzed time interval. The values of the coefficients of pair correlation between dissolved gases in oil and the operating time and between gases in transformers with different states for each of the four variants are given in Table 2.

The values of the correlation coefficients for gases in the defect-free state of the transformers are given in Table 2- $a$ (transformer substation «Gas main» of T-2, Lugansk Electricity-distributing Company). Type of dependencies of gases on the operation time can be described as a state of "complete chaos", because there was no significant correlation of gases over time and among themselves, which is illustrated by the data from Table 2 .

Table 2- $b$ shows the correlation coefficients between gases at substation «Miner's Light» T-1, Kharkov electricity-distributing company. At the diagnosed interval simultaneous growth of methane, ethane and ethylene (acetylene absent) is observed, without development in time. No significant correlation of gases with time, but there is a significant correlation between the gases themselves. Such dynamics of gas changes in time corresponds to external influence on the part of the electric network. In this case, a short-time overload of the transformer.

Table 2-c shows the correlation coefficients between gases for the transformer substation «Fibreglass» T-2, Lugansk Electricity-distributing Company. As seen from Table 2-c, at the diagnosed time interval a significant increase in the concentration of acetylene is observed, with only the acetylene gas of all gases being significantly correlated only with methane, having no significant correlation with time. In this situation, a definite diagnosis is difficult to place, it is necessary to evaluate further dynamics of changes in gas concentrations.

Table 2 Values of the coefficients of pair correlation between the dissolved gases in oil and the time of operation and between the gases in various states of transformers

\begin{tabular}{|c|c|c|c|c|c|c|c|c|c|c|}
\hline № & Transf & Gas & Time & $\mathrm{CO}$ & $\mathrm{CO}_{2}$ & $\mathrm{CH}_{4}$ & $\mathbf{C}_{2} \mathbf{H}_{2}$ & $\mathrm{C}_{2} \mathrm{H}_{4}$ & $\mathrm{C}_{2} \mathrm{H}_{6}$ & $\mathbf{C}_{\Sigma} \mathbf{H}_{\boldsymbol{\Sigma}}$ \\
\hline \multirow{7}{*}{$a$} & \multirow{7}{*}{$\begin{array}{l}\text { Lugansk Electricity-distributing } \\
\text { Company, transformer } \\
\text { substation } \\
\ll \text { Gas main»T-2, } n=19 \\
\rho_{\text {critical, } 17,0,95}=0,456\end{array}$} & $\mathrm{CO}$ & $-0,488$ & 1,00 & 0,146 & 0,191 & $-0,409$ & 0,137 & 0,047 & $-0,032$ \\
\hline & & $\mathrm{CO}_{2}$ & $-0,649$ & 0,146 & 1,00 & 0,209 & $-0,116$ & $-0,084$ & $-0,160$ & $-0,050$ \\
\hline & & $\mathrm{CH}_{4}$ & $-0,480$ & 0,191 & 0,209 & 1,00 & 0,099 & $-0,243$ & 0,404 & 0,485 \\
\hline & & $\mathrm{C}_{2} \mathrm{H}_{2}$ & 0,234 & $-0,409$ & $-0,116$ & 0,099 & 1,00 & 0,360 & 0,313 & $\mathbf{0 , 7 5 1}$ \\
\hline & & $\mathrm{C}_{2} \mathrm{H}_{4}$ & 0,394 & 0,137 & $-0,084$ & $-0,243$ & 0,360 & 1,00 & 0,184 & $\mathbf{0 , 5 5 0}$ \\
\hline & & $\mathrm{C}_{2} \mathrm{H}_{6}$ & 0,038 & 0,047 & $-0,160$ & 0,404 & 0,313 & 0,184 & 1,00 & 0,699 \\
\hline & & $\mathbf{C}_{\Sigma} \mathbf{H}_{\Sigma}$ & 0,087 & $-0,032$ & $-0,050$ & $\mathbf{0 , 4 8 5}$ & $\mathbf{0 , 7 5 1}$ & $\mathbf{0 , 5 5 0}$ & 0,699 & 1,00 \\
\hline \multirow{5}{*}{$b$} & \multirow{5}{*}{$\begin{array}{c}\text { Kharkov Electricity-distributing } \\
\text { Company, transformer } \\
\text { substation «Light Miner's» T-1, } \\
n=8, \rho_{\text {critical }, 6,0,95}=0,707\end{array}$} & $\mathrm{CO}_{2}$ & 0,390 & - & 1,00 & $-0,092$ & - & $-0,092$ & $-0,092$ & $-0,092$ \\
\hline & & $\mathrm{CH}_{4}$ & 0,133 & - & $-0,092$ & 1,00 & - & 1,000 & 1,000 & 1,000 \\
\hline & & $\mathrm{C}_{2} \mathrm{H}_{4}$ & 0,133 & - & $-0,092$ & 1,000 & - & 1,00 & 1,000 & 1,000 \\
\hline & & $\mathrm{C}_{2} \mathrm{H}_{6}$ & 0,133 & - & $-0,092$ & 1,000 & - & 1,000 & 1,00 & 1,000 \\
\hline & & $\mathbf{C}_{\Sigma} \mathbf{H}_{\Sigma}$ & 0,133 & - & $-0,092$ & 1,000 & - & 1,000 & 1,000 & 1,00 \\
\hline \multirow{7}{*}{$c$} & \multirow{7}{*}{$\begin{array}{c}\text { Lugansk Electricity-distributing } \\
\text { Company, transformer } \\
\text { substation } \\
\text { «Fibreglass» } \mathrm{T}-2, n=24 \\
\rho_{\text {critical }, 22,0,95}=0,408\end{array}$} & $\mathrm{CO}$ & $-0,045$ & 1,00 & 0,221 & $-0,406$ & $-0,486$ & $\mathbf{0 , 5 2 4}$ & 0,356 & 0,299 \\
\hline & & $\mathrm{CO}_{2}$ & $-0,551$ & 0,221 & 1,00 & $-0,310$ & $-0,338$ & $-0,014$ & $-0,178$ & $-0,187$ \\
\hline & & $\mathrm{CH}_{4}$ & 0,213 & $-0,406$ & $-0,310$ & 1,00 & 0,700 & 0,022 & 0,100 & 0,432 \\
\hline & & $\mathbf{C}_{2} \mathbf{H}_{2}$ & $\mathbf{0 , 4 5 8}$ & $-0,486$ & $-0,338$ & 0,700 & 1,00 & $-0,422$ & $-0,198$ & $-0,020$ \\
\hline & & $\mathbf{C}_{2} \mathbf{H}_{4}$ & 0,047 & $\mathbf{0 , 5 2 4}$ & $-0,014$ & 0,022 & $-0,422$ & 1,00 & 0,784 & $\mathbf{0 , 8 9 6}$ \\
\hline & & $\mathrm{C}_{2} \mathrm{H}_{6}$ & 0,094 & 0,356 & $-0,178$ & 0,100 & $-0,198$ & 0,784 & 1,00 & $\mathbf{0 , 8 2 0}$ \\
\hline & & $\mathbf{C}_{\Sigma} \mathbf{H}_{\Sigma}$ & 0,191 & 0,299 & $-0,187$ & 0,432 & $-0,020$ & 0,896 & $\mathbf{0 , 8 2 0}$ & 1,00 \\
\hline \multirow{5}{*}{$d$} & \multirow{5}{*}{$\begin{array}{c}\text { Donetsk Electricity-distributing } \\
\text { Company transformer } \\
\text { substation, «Postnikovo» T-1, } \\
n=9, \\
\rho_{\text {critical }, 7,0,95}=0,666\end{array}$} & $\mathrm{CH}_{4}$ & $\mathbf{0 , 7 7 1}$ & - & - & 1,00 & $\mathbf{0 , 9 8 5}$ & $\mathbf{0 , 9 8 5}$ & $\mathbf{0 , 9 5 5}$ & $\mathbf{0 , 9 9 3}$ \\
\hline & & $\mathrm{C}_{2} \mathrm{H}_{2}$ & $\mathbf{0 , 7 7 5}$ & - & - & 0,985 & 1,00 & $\mathbf{0 , 9 6 7}$ & $\mathbf{0 , 9 5 5}$ & $\mathbf{0 , 9 7 8}$ \\
\hline & & $\mathrm{C}_{2} \mathrm{H}_{4}$ & 0,747 & - & - & 0,985 & 0,967 & 1,00 & 0,915 & $\mathbf{0 , 9 9 7}$ \\
\hline & & $\mathrm{C}_{2} \mathrm{H}_{6}$ & $\mathbf{0 , 8 0 3}$ & - & - & $\mathbf{0 , 9 5 5}$ & $\mathbf{0 , 9 5 5}$ & $\mathbf{0 , 9 1 5}$ & 1,00 & 0,940 \\
\hline & & $\mathbf{C}_{\Sigma} \mathbf{H}_{\Sigma}$ & 0,765 & - & - & 0,993 & $\mathbf{0 , 9 7 8}$ & $\mathbf{0 , 9 9 7}$ & 0,940 & 1,00 \\
\hline
\end{tabular}


The values of the correlation coefficients between the gases in the defective transformer are given in Table 2-d (transformer substation «Postnikovo» T-1, Donetsk Electricity-distributing Company). As shown in Table 2, at the diagnosed section for this transformer there has been revealed a significant correlation of gases with time and among themselves. Indeed, on 29.03.1999 on the DGA results there was discovered a thermal defect $t$ $>700^{\circ} \mathrm{C}$, with damage to the solid insulation (overheating of the core, due to eddy currents). It should be noted that the proposed method enabled the detection of this defect six months earlier than the traditional method (a significant correlation between the time of operation and gas concentrations, as well as between the gases was detected in 2 years, whereas at the substation the defect was detected in 2,5 years).

The above examples show that in non-hermetically sealed transformers, a change in state is accompanied not only by an increase in gas concentrations, which is known and widely used, but also by a change in the nature of dependences of the concentration of gas on the duration of operation. If, for non-defects transformers, the values of gas concentrations vary randomly with time (show Fig. 4 ), then when the defect develops, the dependence of the gas concentrations on time (show Fig. 3) is close to the functional one. The random nature of the change in gas concentrations over time, for non-hermetically sealed transformers, is caused both by the processes of diffusion of gases into the atmosphere, and by intense oxidative reactions in conditions of free access of atmospheric oxygen. The impact of emergency operation modes on the part of the electrical net-work (short circuit, overvoltage, overload) lead to a short-term increase in gas concentrations without development over time (show Fig. 5-6). In this case, the gas concentrations can significantly exceed the boundary values. This can lead to false rejection of such transformers. At the same time, an analysis of the dependencies of gas concentrations in time will make it possible to identify the reasons for which the concentrations of gases have increased. It is of fundamental importance that the changes in the character of the gas concentration dependences as a function of time during the development of a defect in the transformer can be detected even before the gas concentrations exceed their boundary values. This allows you to detect defects in transformers at an early stage of their development, when there was no serious destruction of insulation that would ex-tend their resource. In order to systematize the results obtained, we introduce three variables:

$\boldsymbol{K}_{\boldsymbol{l}}$ - characterizes the presence of significant positive correlation between the gases and the time of operation at the diagnosed interval and has two possible values of $\boldsymbol{K}_{\boldsymbol{1}}=$ 0 (no or no significant increase in gas concentration over time) and $\boldsymbol{K}_{\boldsymbol{l}}=1$ (there is a significant increase);

$\boldsymbol{K}_{2}$ - characterizes the presence of significant positive correlation between the gases in the tested transformer at the diagnosed interval, we assume $\boldsymbol{K}_{2}=0$ in the absence of significant correlation between the hydrocarbon gases and $\boldsymbol{K}_{2}=1$, if available;

$\boldsymbol{K}_{3}$ - characterizes the presence of significant correlation between similar gases in adjacent transformers at the substation; $\boldsymbol{K}_{\mathbf{3}}=0$ in the absence of significant correlation, and $\boldsymbol{K}_{3}=1$ if available.
The decision rule for detection of developing defects, for various values of $\boldsymbol{K}_{1}, \boldsymbol{K}_{2}$ and $\boldsymbol{K}_{3}$ can be represented as a Table 3.

The proposed method was tested on an independent sample consisting of transformers with a predetermined diagnosis. The sample included not only defective and defect-free transformers, but also transformers, which were subjected to emergency influences from the electrical network. For all transformers the diagnosis made by the developed method completely coincided with the real condition of the surveyed transformers. The above method is implemented as a separate module of the information-analytical system "SIRENA", for diagnosing the state of equipment of electric power systems. At present, this system is being developed at the Department of "Transmission of Electric Energy" NTU "KhPI".

Table 3 The decision rule for detection of developing defects

\begin{tabular}{|c|c|c|c|}
\hline \multicolumn{3}{|c|}{ Switches } & \multirow{2}{*}{ State } \\
\hline$K_{1}$ & $K_{2}$ & $K_{3}$ & \\
\hline 0 & $\mathbf{0}$ & $\mathbf{0}$ & Most likely the defect is absent. \\
\hline 0 & $\mathbf{0}$ & 1 & $\begin{array}{l}\text { Most likely there is no defect, patterns of } \\
\text { gases are identical for all transformers of a } \\
\text { substation. }\end{array}$ \\
\hline $\mathbf{0}$ & 1 & $\mathbf{0}$ & $\begin{array}{l}\text { Growth of gas concentration without } \\
\text { development over time, external influences. }\end{array}$ \\
\hline $\mathbf{0}$ & 1 & 1 & $\begin{array}{l}\text { Increase in the concentration of gases } \\
\text { without development over time, the patterns } \\
\text { are identical for all transformers of a } \\
\text { substation, external influences. }\end{array}$ \\
\hline 1 & $\mathbf{0}$ & $\mathbf{0}$ & $\begin{array}{l}\text { The growth of the concentration of certain } \\
\text { gases, additional analysis is needed. }\end{array}$ \\
\hline 1 & $\mathbf{0}$ & 1 & $\begin{array}{l}\text { The growth of the concentration of certain } \\
\text { gases, patterns of gases are identical for all } \\
\text { transformers of a substation, external } \\
\text { influences. }\end{array}$ \\
\hline 1 & 1 & $\mathbf{0}$ & Defect. \\
\hline 1 & 1 & 1 & $\begin{array}{l}\text { Most likely the intensive external influence, } \\
\text { additional analysis is needed. }\end{array}$ \\
\hline
\end{tabular}

\section{CONCLUSIONS}

The concentrations of dissolved gases in oil may exceed the maximum values even in the absence of a defect in a transformer. At the same time, the presence of gas concentrations in the range of admissible values is not always a symptom of the lack of a defect. Development of a defect in the insulation is characterized not only by growing concentrations of key gases, but also the emergence of a systematic component in the time dependencies of hydrocarbon gases. A method for interpreting the results of analysis of dissolved gases in oil is proposed, which uses the appearance of a systematic trend of time dependencies of hydrocarbon gases content (and not the concentration of dissolved gases in oil, as in most well-known methods) as a diagnostic criterion of existence of a developing defect. The method allows to identify the processes of ionization aging and thermal degradation in a transformer at an early stage, before there occurred a profound failure of isolation, to recognize the change of gas concentrations associated with exposure of a transformer to operational factors. The performed check showed a fairly high efficiency of the proposed method of detecting defects in high-voltage transformers. 


\section{REFERENCES}

[1] IEC Publication 60599, Interpretation of the analysis of gases in transformer and other oil med electrical equipment in \&, Geneva, Switzerland, 1999.

[2] IEEE Guide for the Interpretation of Gases Generated in Oil-Immersed Transformers, IEEE StandARCd C57.104-2008, Feb. 2009.

[3] DORNENBURG, E. - STRITTMATER, W.: Monitoring Oil Cooling Transformers by Gas Analysis, Brown Boveri Review, Vol. 61, pp. 238$274,1974$.

[4] ROGERS, R. R.: IEEE and IEC Codes to Interpret Incipient faults in Transformers, Using Gas in Oil Analysis, IEEE Trans. on Electrical Insulation, No. 5 (13), pp. 349-354, Oct. 1978.

[5] SOU-N EE 46.501: Diagnosis oil-filled transformer equipment based on the results of chromatographic analysis of free gas with gas relay selected, i gases dissolved in insulating oil, Kiïv, 2007.

[6] RD 153-34.0-46.302-00: Guidelines for the diagnosis of developing defects in transformer equipment based on the results of the chromatographic analysis of gases dissolved in oil, Moskva, 2001.

[7] GRAY, I. A. R.: A Guide to Transformer Oil Analysis, Transformer Chemistry Services, $<$ htpp://www.satcs.co.za/ Transformer Oil Analysis.pdf $>$ (2/2013).

[8] ABRAMOV, V. B. - SHUTENKO, O. V. BAKLAJ, D. N.: Comparative analysis of average risk using the recommended limit concentration of gases dissolved in oil for detecting defects in transformers $110 \mathrm{kV}$, Science news of NTUU "KPI", Kiev, No. 6(98), pp. 16-26, 2014, ISSN 1810-0546.

[9] LVOV, M. U.: Evaluation of indicators' informativeness for monitoring technical condition of isolation of transformer equipment, Power Station, Moscow, No. 12, pp. 44-51, Dec. 2002, ISSN 02014564.

[10] DAVYDENKO, I. V.: Determination of permissible values of controllable parameters of oil-filled equipment, based on the observed data array, Electricity, Moscow, No. 6, pp. 10-21, 2009, ISSN 0013-5380.

[11] ZAKHAROV, A. V.: Detection of defects in oilfilled power transformers as a procedure for testing statistical hypotheses, New in the Russian electro energy sector, Moscow, No. 2, pp. 22-28, Feb. 2001.

[12] SHUTENKO, O. V.: Determining the Limit Concentrations of Gases Dissolved in Oil Using the Minimal Risk Method, Electricity, Moscow, No. 8, pp. 50-60, 2017, ISSN 0013-5380.

[13] ABRAMOV, V. B.: Features of the control of oilfilled electrical equipment based on the results of chromatographic analysis of gases dissolved in oil, Electrical networks and systems, Kiev, No. 4, pp. 7779, Apr. 2012.

[14] DUVAL, M. - LAMARRE, L.: The Duval pentagona new complementary tool for the interpretation of dissolved gas analysis in transformers, IEEE Electrical Insulation Magazine, Vol. 30, Issue 6, pp. 9-12, Nov. 2014.

[15] DUVAL, M.: New techniques for dissolved gas-inoil analysis, IEEE Electrical Insulation Magazine, Vol. 19, No. 2, pp. 6-15, March-April 2003.

[16] KAWAMURA, T. - KAWADA, N. - ANDO, K. YAMAOKA, M. - MAEDA, T. - TAKATSU, T.: Analyzing gases dissolved in oil and its application to maintenance of transformers, SIGRE Session, Report 12-05, Paris, 1986.

[17] CHIH-HSUAN LIU - TUNG-BIN LIN - SHUNYUAN WANG: Integrated power transformer diagnosis using hybrid fuzzy dissolved gas analysis, IEEJ Transactions on Electrical and Electronic Engineering, No. 6 (1), pp. 689-698, Oct. 2015.

[18] DHOTE, N. K. - HELONDE, J. B.: Diagnosis of power transformer faults based on five fuzzy ratio method, WSEAS Transaction on Power System, No. 3, pp. 114-125, July 2012.

[19] SHUTENKO, O. V. - BAKLAJ, D. N.: The analysis of lows of distributions of concentrations of the gases dissolved in oil of high-voltage transformers of not hermetically sealed execution, The Bulletin of the Kharkov National Technical University "KhPI", Kharkov, No. 24 (1067), pp. 102-117, 2014, ISSN 2224-0349.

[20] SHUTENKO, O. V. - ABRAMOV, V. B. BAKLAJ, D. N.: An analysis of the problems encountered in interpreting the results of chromatographic analysis of gases dissolved in oil, The Bulletin of the Kharkov National Technical University "KhPI", Kharkov, No. 59 (1032), pp. 164180, 2013, ISSN 2224-0349.

[21] SHUTENKO, O. V. - BAKLAJ, D. N. OSTRIKOVA, T. A. - MELNIK, N. Ju.: Analysis of the causes of gassing in the power transformers based on a study of correlations between dissolved in oil gases, Lighting and electricity, Kharkov, No. 3, pp. 72-81, 2012, ISSN 2415-3923.

Received November 28, 2017, accepted February 8, 2018

\section{BIOGRAPHY}

Oleg Shutenko was born on 17.11.1970. In 1992 he graduated from the Kharkov Polytechnic Institute, for specializing in «Electrical insulating, capacitor and cable equipment», in the electric power faculty. In 2010 he defended his thesis on the topic «Improvement of diagnostics of power high-voltage transformers on the basis of analysis of regularities of long-term aging of oils», for specializing in «Technique of strong electric and magnetic fields». Since 2002 he is working as a tutor with the Department of electric power transmission, NTU "KhPI". His research focuses on diagnostics of the insulation state of high-voltage oil-filled equipment, studying the aging processes of isolation, developing mathematical models for diagnosing equipment defects, estimating and predicting its residual resource. In addition, he also investigates questions related with the highvoltage engineering and electro-physics. 